\title{
Wind Tunnel Testing for Blended Wing Body Aircraft with Canard
}

\author{
Zurriati Mohd Ali, Wahyu Kuntjoro, Wirachman Wisnoe
}

\begin{abstract}
The Blended Wing-Body (BWB) aircraft is an unconventional aircraft that offers the aerodynamics performance advantages compared to the conventional aircraft. This type of aircraft has a unique design where the main body is blended together with the wing that gives the additional lift of the aircraft. In contrast to the conventional aircraft, the BWB has a poor stability due to the absence of the tail. A possible solution is by using a horizontal control surface, the canard, to improve the stability of the BWB. For this purpose, a comprehensive investigation of the aerodynamic behavior of the BWB with canard is important. The experimental works were performed on a scale model and tested in a low speed wind tunnel. Angles of attack, $\alpha$ varied from -10 to 10 degree, as well as canard setting angles, $\delta$. The investigations were carried out at Reynolds Number of 3 x 105 . The results show that the canard contributes a small lift forces but with the increase of drag to the BWB. On the stability issue, the canard with higher aspect ratio has a significant effect towards the moment coefficient of the aircraft configuration where it improves the trim angle and moment at zero lift. All these results are encouraging enough for the canard to be considered as mechanism for controlling the longitudinal mode of the BWB aircraft.
\end{abstract}

Keywords - Wind Tunnel, Blended Wing Body, Canard, Aerodynamics.

\section{Introduction}

BWB has a unique configuration. With the absence of vertical tail (elevator), this type of aircraft, also known as a tailless aircraft, has a problem in longitudinal control (pitching moment) which gives challenges for a BWB aircraft in stability and control aspect. The Northrop Flying Wing (B-49) is the example of the tailless aircraft which is unstable and lack computer control necessary to make it flyable. Due to the lack of tail as a horizontal control surface, researchers [1-10] did substantial work to determine the best allocation of control surfaces through experiments and computational studies for BWB's moment control.

\section{Zurriati Mohd Ali}

Univesiti Teknologi MARA, Kampus Pasir Gudang, Johor Malaysia.

\section{Wahyu Kuntjoro, Professor \\ Univesiti Teknologi MARA, Shah Alam \\ Malaysia}

Wirachman Wisnoe, Professor

Univesiti Teknologi MARA, Shah Alam

Malaysia
The elevons, ailerons, twist inverse design, augmentation of aerodynamic controls with the propulsion system, belly flaps and canard was seen as an alternative to replace the elevator as horizontal stabilizer. Ideally, one can say that BWB is a modern future aircraft having good performance and being aerodynamically efficient. The Universiti Teknologi MARA (UiTM) BWB's research and development has started since 2005.

Figure 1. 1 (a) to (d) shows the evolution of UiTM's BWB aircraft. The BWB in Figure 1.1 (a) was the first design known as BWB-Baseline I. It has sharp edges, broad body, small wing area and elevator as a pitching moment control. Due to ineffective control of elevator, the BWB was then modified, while maintaining the wing span, body length and reference planform area to BWB-Baseline-II as shown in Figure 1.1 (b). The BWB-Baseline-II was a completelyrevised and redesigned version of BWB-Baseline- I [11]. Its feature has a simpler planform, broader-chord wing and slimmer body than previous. The small control canard is incorporated on Baseline-II since the center body elevator located at the aft of the body of BWB-Baseline I is ineffective as the pitching moment produced, causing change of trim impossible [12]. After that, the studies of BWB with canard were aggressively done through experimental and computer simulation [13-16]. The small size of canard was found as one of the reasons of the instability in BWB's control. Modification on the BWBBaseline II has been made to improve trim flight and controllability. The outer wing has been twisted down 7.0 degree and dihedral angle increased up to 5.0 degree. This modified wing-body form was combined with the larger canard, known as Baseline II-E2 as shown in Figure 1.2 (c). In this form, its estimation maximum $\mathrm{L} / \mathrm{D}$ is approximately 19 and statically stable in longitudinal direction only for flight within low angles of attack. However, this L/D is greater than Baseline II version, which is 15 at $\alpha=8.0$ degree.

The BWB planform used in this study has been derived from a previous research by Nasir et al.[14]. This study, therefore, is considered a continuation of earlier efforts. However, the BWB being used for this study has a rectangular shape of canard and the aspect ratios having constant area were varied, as shown in Figure 1.1 (d).

The objectives of this study are to obtain aerodynamic characteristics: lift, drag and moment coefficient of a UiTM's BWB aircraft with canard and to determine the effective aspect ratio of canard for UiTM BWB at low subsonic speed, with Mach number 0.1. This extend to the role of the canard in providing the best lift to drag ratio and significant coefficient of moment with respect to the canard setting angles, at a range of low angles of attack, $\alpha$ between -10 to 10 degree. In this context, the aerodynamic performances were evaluated with wind tunnel experiments. 
Proc. of The Fourth Intl. Conf. On Advances in Mechanical, Aeronautical and Production Techniques - MAPT 2015 Copyright $(\subseteq$ Institute of Research Engineers and Doctors, USA .All rights reserved. ISBN: 978-1-63248-072-9 doi: 10.15224/ 978-1-63248-072-9-61

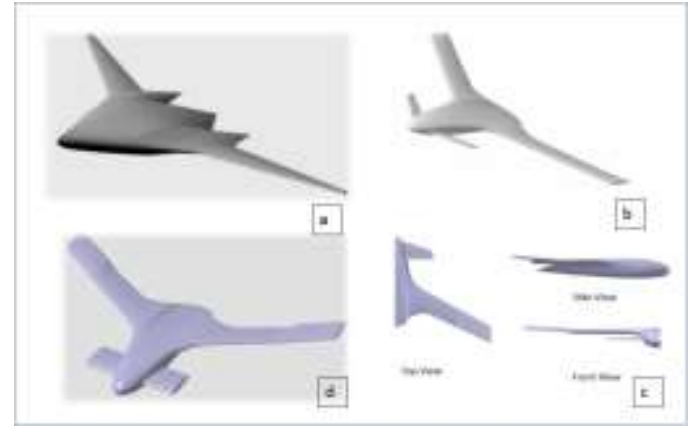

Figure 1. 1: UiTM BWB evolution

\section{Experimantal Method}

\section{A. Instrumentation and Apparatus}

A half-body was used since the BWB is symmetrical in shape.The model was mounted on an arc-sector turntable, with pitch, yaw and roll capable of -10 to 40 degree, \pm 90 degree and \pm 15 degree, respectively.

The wind tunnel equipped with six-component balance was used to measure the loads on the BWB configuration. The computer program using DARCS2D software monitored the temperature, airspeed, pitch and yaw of the aircraft model in the wind tunnel. The obtained data was measured on the balance strain gauge and was translated to forces and moment. The resulting forces and moments for each point at a given angle of attack are automatically recorded in the data files.

The wind tunnel experiment model is one-sixth scale BWB equipped with canard. This scale was chosen for its ease of manufacturing and to fit the size constraint imposed by $0.5 \mathrm{~m} \times 0.5 \mathrm{~m} \times 1.25 \mathrm{~m}$ long test section. The shape of the canard is rectangular. Only half-body is used since the BWB is symmetrical in shape. The model was built with the help of the CAD package, CATIA and manufactured by a computer numerical control $(\mathrm{CNC})$ milling machine. The models were made from aluminum. Figure 1.2 shows the isometric drawing of the wind tunnel model. Table 1 show the wind tunnel geometric characteristic of the half-body of BWB.

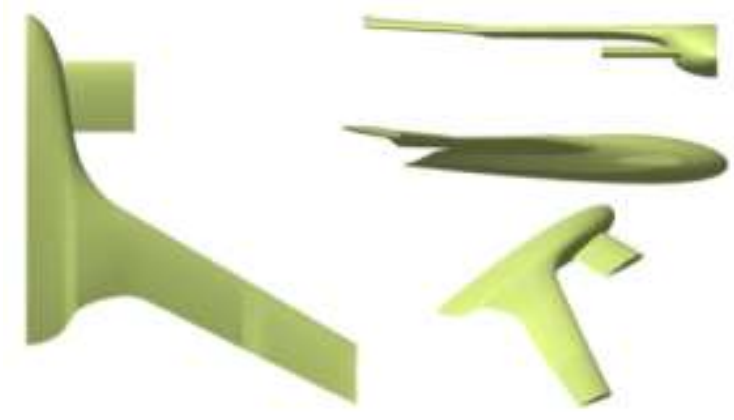

Figure 1. 2: Isometric drawing of BWB
Table 1: BWB model geometric characteristics

\begin{tabular}{|l|l|l|}
\hline Description & Symbol & Value \\
\hline Reference Area & $\mathrm{A}_{\mathrm{w}-\mathrm{b}}$ & $0.03995 \mathrm{~m}^{2}$ \\
\hline $\begin{array}{l}\text { Mean Aerodynamic } \\
\text { Chord }\end{array}$ & $\mathrm{MAC}$ & $0.114 \mathrm{~m}$ \\
\hline Body Length & & $0.348 \mathrm{~m}$ \\
\hline Wing Span (half) & $1 / 2 \mathrm{~S}_{\mathrm{w}}$ & $0.348 \mathrm{~m}$ \\
\hline Canard Area & $\mathrm{A}_{\mathrm{c}}$ & $0.005 \mathrm{~m}^{2}$ \\
\hline Aspect Ratio & $\mathrm{AR}_{\mathrm{c}}$ & $2,4,6,8$ \\
\hline
\end{tabular}

Based on the literature survey, the ranges of canard aspect ratio that have been studied are between 2 to 8 , respectively. Therefore, four canards with different aspect ratio were used in the tests.

\section{B. Repeatability Test}

The repeatability of the external balance and wind tunnel operation would have a significant meaning, since the values to be compared was small. The repeatability and reproducibility check-up during model test were done several times. The model configuration used for repeatability test was a BWB without canard, respectively. Figures 1.3 present the lift coefficient repeatability. The test data shows that the two runs have almost identical lift curves pattern. The curve before BWB stall region presents around 0.03 difference in maximum lift coefficient. Results display a good agreement at a single glance. To check repeatability more closely, data are compared at linear region using linear curve fitting. The average difference at linear regions is 0.0017 , and it can be negligible. Therefore, one can assume that the data of external balance and wind tunnel operating conditions provide a reliable level of repeatability during the model test.

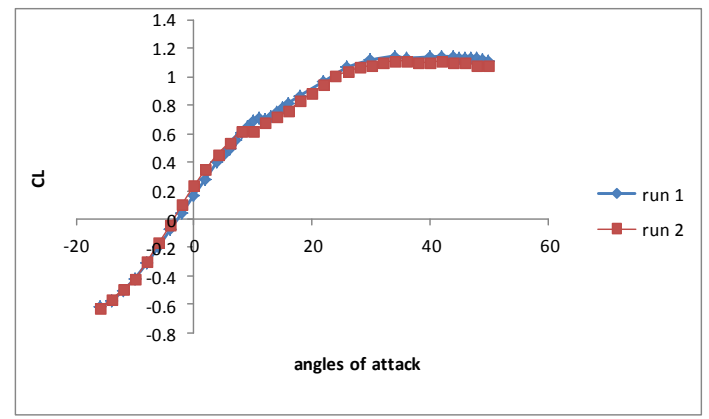

Figure 1. 3: Lift coefficient repeatability

\section{Experimental Results}

The experimental result obtained for BWB model is given in this chapter. The result will consist of lift, drag, liftto-drag and moment coefficient for various angles of attack, $\alpha$ and canard deflection angles.

\section{A. Lift Coefficient, $C_{L}$}

Figures 2.1 to 2.3 represent the measured lift curve for each canard setting angles examined in the study. From the 
Proc. of The Fourth Intl. Conf. On Advances in Mechanical, Aeronautical and Production Techniques - MAPT 2015 Copyright $(\subseteq$ Institute of Research Engineers and Doctors, USA .All rights reserved. ISBN: 978-1-63248-072-9 doi: 10.15224/ 978-1-63248-072-9-61

figures, it is possible to observe that the lift is increased as the angles of attacks are increased. The slope of lift coefficient is affected by the canard aspect ratio that is small.

Figure 6.1 (a) shows the lift coefficient with respect to angles of attack, $\alpha$ for BWB without and with canard (at $\delta=0$ degree). From observation, at $\alpha=-10$ to -4 degree, the lift is increased as the canard aspect ratio is increased. However, the lift produced by the BWB with canard AR 2 is lower compared to without canard. The lift is continuously increased as $\alpha$ increase. It can be seen that starts from $\alpha=0$ to 8 degree, the BWB with canard AR 6 has the highest lift. At $\alpha=10$ degree, it can be seen that BWB without canard has the lowest lift compared to BWB with canard. The maximum lift coefficient, $\mathrm{C}_{\mathrm{L}, \max }$ for $\mathrm{BWB}$ without canard is 0.57 , and with canard, the lift is increases to $0.61(\mathrm{AR}=2)$, $0.70(\mathrm{AR}=4), 0.68(\mathrm{AR}=6)$ and $0.72(\mathrm{AR}=8)$, all are at $\alpha$ $=10$ degree, respectively. The BWB without canard has a slope of 0.06 per degree and with canard; the lift slope, $C_{L \alpha}$ is around 0.064 to 0.068 per degree, depending on canard aspect ratios.

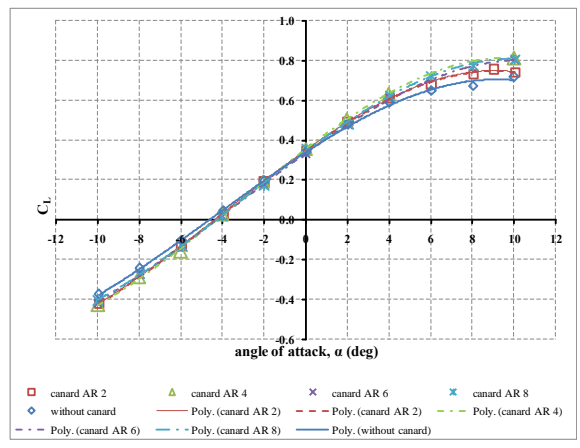

Figure 2. 1: Lift curves of BWB with different canard aspect ratio at different setting angles, $\delta=0$ degree

The BWB with canard AR 6 has the highest lift when the canard is deflected to 5 degree, as seen in Figure 2.2. At negative angles of attack ( $\alpha=-10$ to -2 degree), the lift is lowered for BWB with canard (except BWB with canard AR 6) compared to without canard. As $\alpha$ increased, the lift increased and it can be seen, by adding canard, BWB has a greater lift compared to without canard. At $\alpha=10$ degree, the $\mathrm{C}_{\mathrm{L}}$ is $0.63(\mathrm{AR}=2), 0.70(\mathrm{AR}=4), 0.75(\mathrm{AR}=6)$ and 0.72 $(\mathrm{AR}=8)$, which is not much of a difference from the case where the canard is not deflected. The lift slope $C_{L \alpha}$ is in between 0.059 to 0.067 per degree, depending on canard aspect ratios.

Figure 2.3 shows the lift coefficient curves when the canard is deflected to 10 degree. The graph shows the BWB with canard AR 2 has a lower lift compared to without canard, when the aircraft is pitching from -10 to 6 degree. However, as $\alpha$ increased, it can be seen that the lift is increased. By adding canard, the lift is greater where the BWB with AR 6 configuration has the highest lift. The maximum lift is achieved when $\alpha=10$ degree and the $C_{L}$ is $0.65(\mathrm{AR}=2), 0.70(\mathrm{AR}=4), 0.74(\mathrm{AR}=6)$ and $0.72(\mathrm{AR}=8)$. The lift slope $\mathrm{C}_{\mathrm{L} \alpha}$ is at the range of 0.053 to 0.059 per degree where it is lower compared to where the canard is at $\delta=0$ and 5 degree.

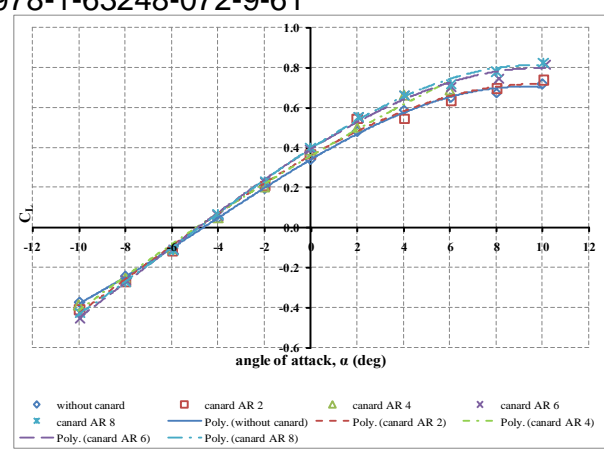

Figure 2. 2: Lift curves of BWB with different canard aspect ratio at different setting angles, $\delta=5$ degree

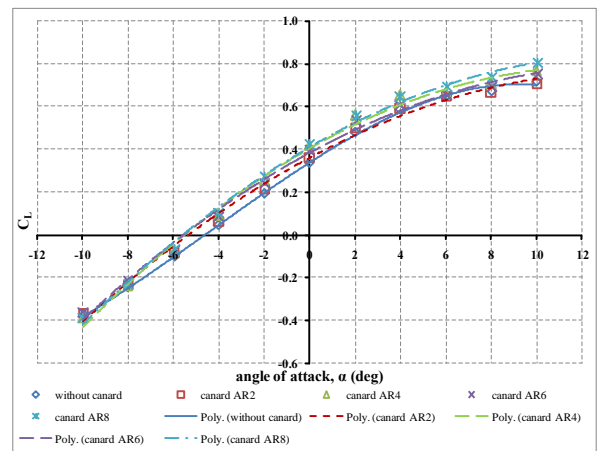

Figure 2. 3: Lift curves of BWB with different canard aspect ratio at different setting angles, $\delta=10$ degree

\section{B. Drag Coefficient, $C_{D}$}

Figures 2.4 to 2.6 show a drag coefficient versus angles of attack, for various canard aspect ratios. The curves are in parabolic trend, whereby increasing the angles of attack will cause a higher drag. From close observation, it shows that the drag coefficient of the BWB with canard was higher than without canard.

Figure 2.4 shows drag coefficient curves when the canard is not deflected ( $\delta=0$ degree). From observation, the drag is higher when the canard is employed to the BWB body, depending on the canard aspect ratio. However at, $\alpha=$ -2 to 8 degree, the BWB with canard AR 4 has a lower drag compare to without canard. The drag coefficient at zero angle of attack, $\mathrm{C}_{\mathrm{D} 0}$ was around 0.03 for $\mathrm{BWB}$ with and without canard. The drag is rapidly increased as $\alpha$ of the BWB is increased from 4 to 10 degree. The drag coefficient range for $\mathrm{BWB}$ with canard AR 2 was within 0.02 to 0.12 .

As the canard is deflected to 5 degree, it can be seen that the BWB with canard AR 6 has the highest drag coefficient when $\alpha$ is increased, shown in Figure 2.5. It also can be seen by adding canard the drag which is higher than without canard. The $\mathrm{C}_{\mathrm{D} 0}$ is higher, which is around 0.045 compared to the canard when it is not deflected. Similarly to the previous, the drag was rapidly increased as started from $\alpha=4$ degree and it varies from 0.016 to 0.141 .

Figure 2.6 shows the BWB with canards at $\delta=10$ degree. At negative angles of attack ( $\alpha=-10$ to -4 degree), the drag coefficient is decreased with the increasing of $\alpha$. At this range of angles, it can be seen that BWB with canard AR 2 has the highest lift. However, as $\alpha$ is continuously increased, the drag coefficient of BWB with AR 6 is getting higher. The drag at $\alpha=0$ degree is around 0.02 to 0.04 , depending on the canard aspect ratio. The range of drag coefficient of BWB when canard is at angle 10 degree is approximately 0.04 to 0.130 . 
Proc. of The Fourth Intl. Conf. On Advances in Mechanical, Aeronautical and Production Techniques - MAPT 2015 Copyright (@) Institute of Research Engineers and Doctors, USA .All rights reserved. ISBN: 978-1-63248-072-9 doi: 10.15224/ 978-1-63248-072-9-61

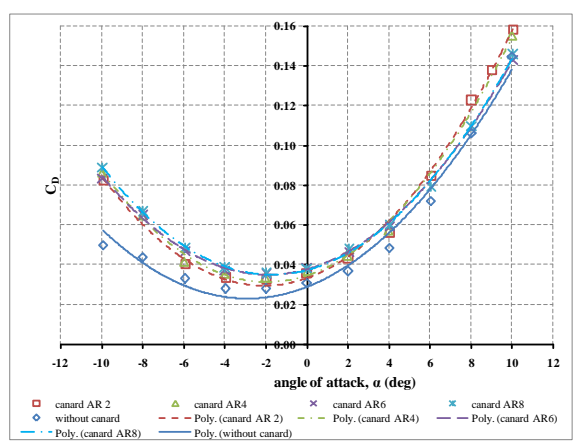

Figure 2. 4: Drag curves of BWB with different canard aspect ratio at different setting angles, $\delta=0$ degree

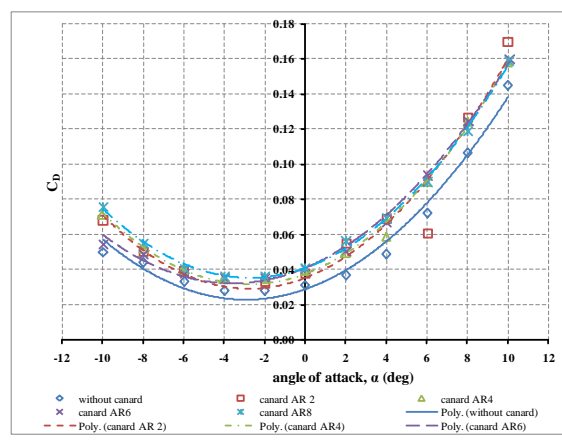

Figure 2. 5: Drag curves of BWB with different canard aspect ratio at different setting angles, $\delta=5$ degree

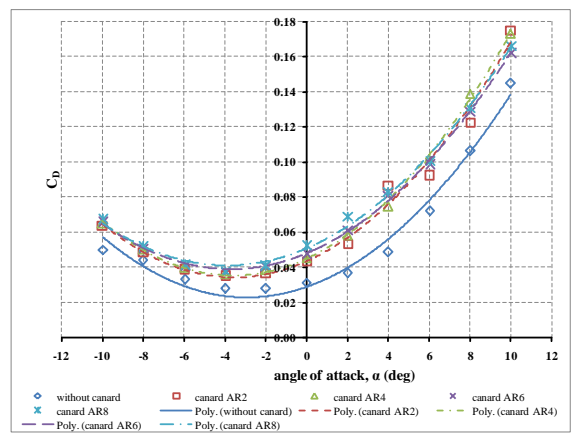

Figure 2. 6: Drag curves of BWB with different canard aspect ratio at different setting angles, $\delta=10$ degree

\section{Moment Coefficient, $\boldsymbol{C}_{M}$}

Plots in Figures 2.7 to 2.9 show the effect of canard aspect ratio to moment coefficient, $\mathrm{C}_{\mathrm{M}}$ with respect to angles of attack, $\alpha$. For these results, the pitching moment versus angles of attack was measured at $19.8 \%$ MAC. In general, the overall trend is similar to $\mathrm{C}_{\mathrm{L}}-\alpha$ curve except the later has a negative slope. As the angle of attack increased, it can be seen that the moment is decreased.

In Figure 2.7, it shows the moment with respect to angles of attack at $\delta=0$ degree. It can be observed that the change of moment with respect to angles of attack, $C_{M, \alpha}\left(\mathrm{dC}_{\mathrm{M}} / \mathrm{d} \alpha\right)$ was negative and achieved within $\alpha=-10$ to 4 degree. The $\mathrm{C}_{\mathrm{M}, \alpha}$ of $\mathrm{BWB}$ without canard was -0.026 per degree and decreased as the canard existed. The plots show that the $\mathrm{C}_{\mathrm{M}, \alpha}$ of $\mathrm{BWB}$ with $\mathrm{AR} 2$ to 8 was around -0.017 to 0.001 per degree. The moment at zero angle of attack, $\mathrm{C}_{\mathrm{M}, \alpha=0^{\circ}}$ for BWB without canard is around -0.132. Existence of canard increased the $\mathrm{C}_{\mathrm{M}, \alpha=0^{\circ}}$ to $\approx-0.1$ for canard $\mathrm{AR} 2,4$ and 8 and 0.03 for canard AR 6 .
The $\mathrm{C}_{\mathrm{M}, \alpha}$ of a BWB with canard was around -0.017 to 0.008 per degree as the canard was deflected to 5 degree, as shown in Figure 2.8. It has been clearly seen that, existence

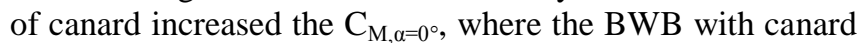
AR 8 has a positive $C_{M, \alpha=0^{\circ}}$ of 0.01 . The angle of attack where pitch moment is zero, is known as trim angle of attack $\alpha_{\text {trim }}$. The $\alpha_{\text {trim }}$ BWB with canard AR 8 was around $1^{\circ}$. Also, there has been a small increment of $C_{M, \alpha=0^{\circ}}$ for BWB with canard AR 4 compared to canard when it was not deflected. However, the $\mathrm{C}_{\mathrm{M}, \alpha=0^{\circ}}$ of BWB with canard AR 6 has reduced to -0.08 and this has been similar to canard AR 2 .

As the canard was deflected 10 degree Figure 2.8, it was observed that the pitching moment slope, $\mathrm{C}_{\mathrm{M}, \alpha}$ was around 0.014 to -0.03 per degree. The BWB with canard has a positive $C_{M, \alpha=0^{\circ}}$ compared to without canard. The range of $\mathrm{C}_{\mathrm{M}, \alpha=0^{\circ}}$ was around 0.02 to 0.04 and trim angles of attack attainable was 0 to 2 degree, depending on canard aspect ratio.

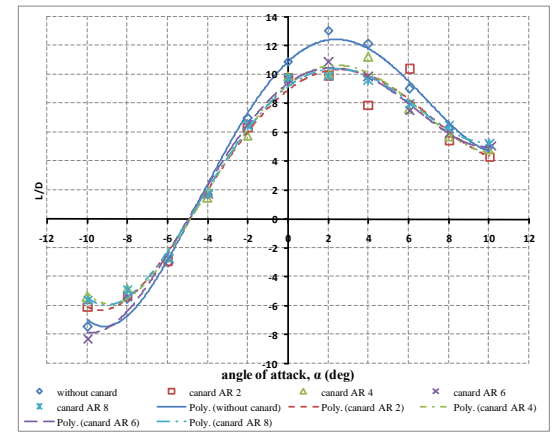

Figure 2. 7: Moment curves of BWB with different canard aspect ratio at different setting angles, $\delta=0$ degree

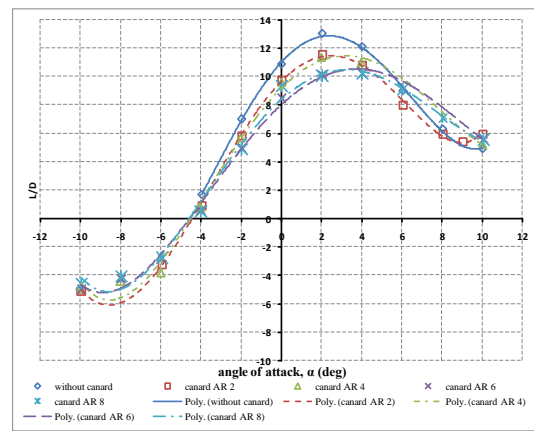

Figure 2. 8: Moment curves of BWB with different canard aspect ratio at different setting angles, $\delta=5$ degree

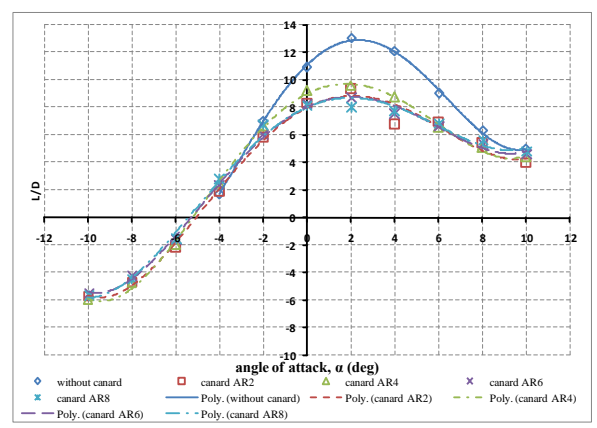

Figure 2. 9: Moment curves of BWB with different canard aspect ratio at different setting angles, $\delta=5$ degree 


\section{Conclusion}

A new control surface consisting of a canard located at the front of the major wing of the BWB was studied. It involves the determination of aerodynamics characteristic $\left(\mathrm{C}_{\mathrm{L}}, \mathrm{C}_{\mathrm{D}}, \mathrm{L} / \mathrm{D}\right.$ and $\left.\mathrm{C}_{\mathrm{M}}\right)$ of BWB incorporated with the canard. Apart from this, it leads to the selection of canard which has a fixed area, but different aspect ratio that provides the aircraft with the maximum lift with less drag and better pitching moment.

Adding the canard surface has a small effect on the lift curves slope at low angles of attack, but increased at higher angles of attack. The increase of lift was proportional to higher canard aspect ratio. This is contrary to what have been seen from the flow visualization where most of the canards were already stall at higher angles of attack. These results, however, do not come as a surprise; since for both low and high canard aspect ratios at positive or negative canard setting angles, the canard surface stalled at angles of attack lower than that for wing-body stall. The studies show that the main contributor of the lift of the BWB comes from the body and wing itself. Considering its small size, the canard's contribution of lift enhancement to the BWB is not significant.

The canard causes a significant change in moment coefficient of the BWB. Its setting angles are deflected positive to maintain trim angle and positive moment at zero lift. The result shows that the BWB with canard fulfill the static stability criteria. However, as the canard setting is decreased to negative, the result is unacceptable.

\section{Acknowledgment}

The authors would like to thank for the support given to this research by Ministry of Higher Education (MOHE) and Universiti Teknologi MARA (UiTM).

\section{References}

[1] S. M. Waters, M. Voskuijl, L. L. M. Veldhuis, and F. J. J. M. M. Geuskens, "Control allocation performance for blended wing body aircraft and its impact on control surface design," Aerospace Science and Technology, vol. 29, pp. 18-27, 2013.

[2] S. P. Pao, R. T. Biedron, M. A. Park, C. M. Fremaux, and D. D. Vicroy, "Navier-Stokes Computations of Longitudinal Forces and Moments for a BlendedWing Body," in 43rd AIAA Aerospace Sciences Meeting and Exhibit, Reno, NV, 2005.

[3] Y. D. Staelens and R. F. Blackwelder, "Computer Simulation of Landing, Takeoff and Go-around of

[4] Blended-Wing-Body Airplane with Belly-Flaps," presented at the 46th AIAA Aerospace Sciences Meeting and Exhibit, Reno, Nevada, 2008

[5] N. Qin, A. Vavalle, A. L. Moigne, M. Laban, K. Hackett, and P. Weinerfelt, "Aerodynamic Studies For Blended Wing Body Aircraft," presented at the 9th AIAA/ISSMO Symposium on Multidisciplinary Analysis and Optimization, Atlanta, Georgia, 2002.

[6] R. E. M. Nasir, W. Kuntjoro, and W. Wisnoe, "Longitudinal Static Stability of a Blended Wing-Body Unmanned Aircraft with Canard as Longitudinal Control Surface," Journal of Mechanical Engineering, vol. 9, pp. 99-121, 2012.

[7] N. u. Rahman, "Propulsion and Flight Controls Integration for the Blended Wing Body Aircraft," PhD Thesis, Aerospace Sciences, Cranfield University, 2009.

[8] J. Chung, E. Hallberg, S. Cox, and M. Plyler, "Landing Pitch Control Analysis for a Blended Wing
[9] Body UCAV," presented at the 48th AIAA Aerospace Sciences Meeting Including the New Horizons Forum and Aerospace Exposition, Orlando, Florida, 2010.

[10] M. A. Page, J. P. Whitlock, and M. W. Wilks, "Variable Size Blended Wing Body," United States Patent, 14 May 2003, 2008.

[11] R. E. M. Nasir, K. W, W. Wisnoe, Z. M. Ali, N. F. Reduan, F Mohamad, et al., "Preliminary Design of "Baseline-II" Blended Wing-Body (BWB) Unmanned Aerial Vehicle (UAV): Achieving Higher Aerodynamic Efficiency Through Planform Redesign and Low-Fidelity Inverse Twist Method," in 3rd Engineering Conference on Advancement in Mechanical and Manufacturing For Sustainable Environment (EnCon 2010), Sarawak, Malaysia, 2010.

[12] R. E. M. Nasir, W. Kuntjoro, W. Wisnoe, and A. M. I. Mamat, "The Effect of Centre Elevator on Aerodynamics of UiTM Baseline-1 Blended Wing Body (BWB) Unmanned Aerial Vehicle (UAV) at Low Subsonic Speed," presented at the International Conference on Advancement in Mechanical Engineering (ICAME), Shah Alam, 2009.

[13] W. Wisnoe, W. Kuntjoro, F. Mohamad, R. E. M. Nasir, Nor F Reduan, and Z. Ali, "Experimental Results Analysis for UiTM BWB

Baseline-I and Baseline-II UAV Running at 0.1 Mach number," International Journal Of Mechanics, vol. 4, 2010.

[14] R. E. M. Nasir, Z. Ali, W. Kuntjoro, and W. Wisnoe, "Investigation on Aerodynamic Characteristics of Baseline-II E-2 Blended WingBody Aircraft with Canard via Computational Simulation," in The International Meeting on Advances in Thermofluids (4th IMAT), Melaka, 2011.

[15] R. E. M. Nasir, W. Kuntjoro, W. Wisnoe, Z. M. Ali, N. F. Reduan, F. Mohamad, et al., " Aerodynamics and Longitudinal Static Stability of Baseline - II Blended Wing Body Aircraft Variants," in 2010 International Conference on Advances in Mechanical Engineering (ICAME 2010) Shah Alam Convention Center, Malaysia, 2010.

[16] N. F. Reduan, W. Wisnoe, W. Kuntjoro, R. E. M. Nasir, F. Mohamad, and Z. M. Ali, "Study of Aerodynamics Characteristic of BWBBaseline II," in 2010 International Conference on Advances in Mechanical Engineering (ICAME 2010), Shah Alam Convention

\section{About Author :}

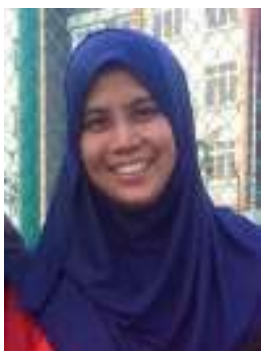

Zurriati Mohd Ali is a lecturer in Faculty of Mechanical Engineering,Universiti Teknologi MARA Cawangan Johor, Kampus Pasir Gudang. Her current research is Aerodynamics and Turbulent Flow around the aircraft. 